\title{
The relationship of symptomatic thoracolumbar disc herniation and Scheuermann's disease
}

\author{
Ning Liu · Zhongqiang Chen • Qiang Qi • \\ Zefeng Shi
}

Received: 21 April 2013/Revised: 7 November 2013/Accepted: 7 November 2013/Published online: 17 November 2013

(C) The Author(s) 2013. This article is published with open access at Springerlink.com

\begin{abstract}
Purpose Symptomatic disc herniations in the thoracolumbar spine between T10/11 and L1/2 can be collectively called thoracolumbar disc herniation (TLDH). The etiology of this disorder is unclear. However, it is interesting that we have noted numerous TLDH patients have radiographic features of another spinal disorder which is Scheuermann's disease (SD). The purpose of this study is to investigate the relationship between symptomatic TLDH and SD in a symptomatic TLDH cohort.

Methods A cohort of 63 patients with symptomatic TLDH, who had surgery was investigated. Incidences of associated SD and four radiographic signs of SD that were Schmorl's node, irregular vertebral end plate, posterior bony avulsion of the vertebra and wedge-shaped vertebra, average thoracolumbar kyphotic angle and incidences of disc herniation at segments with and without radiographic signs of SD were examined. Data from the TLDH group were compared with 57 patients undergoing surgery for lower lumbar disc herniation (LDH, L3/4-L5/S1) in the same period.

Results The incidences of the four radiographic signs of SD and the incidence of associated SD were all significantly higher in the TLDH group than in the LDH group. $95.2 \%$ of the patients in the TLDH group were diagnosed with SD (either classical SD or its atypical form). The average thoracolumbar kyphotic angle of the TLDH group
\end{abstract}

N. Liu $\cdot$ Z. Chen $(\varangle) \cdot$ Q. Qi

Department of Orthopaedics, Peking University Third Hospital,

No.49 North Garden Road, Beijing 100191, China

e-mail: zhongqiang_chen@yahoo.com; bioning@yahoo.com

Z. Shi

Department of Orthopaedics, The People's Hospital of Guangxi

Zhuang Autonomous Region, Nanning, China was $16.9^{\circ}$, while that of the LDH group was $7.6^{\circ}$ $(P=0.000)$. In the TLDH group, the incidences of disc herniation at segments with radiographic signs of SD were all significantly higher than at segments where no sign of SD was found.

Conclusions The high proportion of associated SD and the tendency of SD's signs to promote disc herniation in symptomatic TLDH patients suggest a close relationship between these two disorders. Symptomatic TLDH should be seen as a truly different surgical entity, that is, a special form of SD rather than just an indicator of a failing back.

Keywords Thoracolumbar disc herniation .

Scheuermann's disease

\section{Introduction}

In clinical practice, symptomatic disc herniation at the thoracolumbar junction from T10-11 to L1-2 can be collectively called thoracolumbar disc herniation (TLDH) [1] . High rate of neurological disability has been noted in patients with this disorder and its surgical results differ significantly from those of ordinary low lumbar disc herniation (LDH) at the levels from L3-4 to L5-S1 [2-4]. Unfortunately, at present, much is unknown about the etiology and pathogenesis of symptomatic TLDH.

We noted that numerous symptomatic TLDH patients visiting our institution had 4 radiologic features which are Schmorl's nodes (SN), irregular vertebral end plates (IE), posterior bony avulsions of the vertebrae (PBA) and wedge-shaped vertebrae (WV). Interestingly, these changes were all related to another spinal disorder: Scheuermann's disease (SD) [5-12]. SD was initially named after Scheuermann's first description of a structural thoracic kyphosis 
with more than 3 wedged vertebrae that mainly affected adolescents [5], but it was subsequently recognized that other than Scheuermann's kyphosis, the pathological changes of SD involved disc lesions characterized by the above features, most commonly at the lumbar and thoracolumbar regions [6-10]. Moreover, there was a portion of SD patients who manifested disc lesions and only one or two wedged vertebrae but did not have significant Scheuermann's kyphosis. Accordingly, they were diagnosed with "atypical SD" or "lumbar (thoracolumbar) SD" [6, 9]. The "lumbar Scheuermann's" was first described in 1957 by Edgren and Vaino as "osteochondrosis juvenilis lumbalis". Recently, it has gradually been noted that SD, including its atypical forms, is not uncommon, and indeed, radiological signs of it may be present in 18-40 \% of the population [13]. The radiologic similarity between TLDH and SD made it attractive to assume that these two disorders have a close relationship, which could help to explain the etiology of TLDH. Although symptomatic TLDH in the context of SD has been recognized to occur [11, 13-17], the very limited number of cases reported made it difficult to judge whether the simultaneous occurrence of these two infrequent disorders is simply due to random association or is indicative of a more substantial relationship between the two.

In this study, a retrospective radiographic review was conducted on 63 symptomatic TLDH patients to investigate the relationship between TLDH and SD by examining the incidences of associated SD and its radiologic signs in the TLDH patients. Another group of $57 \mathrm{LDH}$ patients served as controls. In addition, the radiologic signs of SD and the corresponding disc herniations were compared in the TLDH group.

\section{Materials and methods}

\section{Patients}

Seventy-one patients underwent surgery after a diagnosis of symptomatic TLDH (T10/11-L1/2) at our department between June 2006 and June 2011. Among them, eight patients who had previous spinal surgery or incomplete radiographic materials were excluded. Ultimately, 63 patients were enrolled as the TLDH group. There were 50 males and 13 females with a mean age of 43.9 (22-72) years. All patients had neurologic symptoms that warranted surgery. The presenting symptoms were lower extremity weakness in 44 patients $(69.8 \%)$, nonradicular or radicular leg pain in $23(36.5 \%)$, axial back pain in $6(9.5 \%)$ and bladder dysfunction in $7(11.1 \%)$. Seven patients presented with symptoms after traumatic events [swimming (1), dancing (1), back sprain (2), lifting heavy objects (1), back massage (1) and jumping on flat ground (1)]. Because these events were more related to daily stress than to violent accidents, these 7 patients were not excluded from the series. The other 56 patients had insidious onset of symptoms. Physical examinations revealed myelopathy in 15 patients $(23.8 \%)$, radiculopathy in $29(46.03 \%)$, both myelopathy and radiculopathy in $18(28.6 \%)$ and cauda equina syndrome in $11(17.5 \%)$. Fifty patients had singlelevel herniation, 10 had two-level herniation, and the other 3 had three-level of herniation. A total of 79 herniated discs were found in the patients between T10/11 and L1/2, with 3 discs at T10/11, 33 discs at T11/12, 27 at T12/L1 and 16 at L1/2. All patients had complete MR images that included levels T10/11 to L5/S1 and reconstructive CT images that visualized from $\mathrm{T} 10$ to $\mathrm{S} 1$.

Data from these TLDH patients were compared with a group of controls that presented with ordinary LDH. They were randomly sampled by SPSS from 1,150 patients surgically treated in the same period for symptomatic LDH from level L3/4 to L5/S1. At first, the sample size was set at 63 cases because there were 63 patients in the TLDH group. Exclusion criteria for the control group were associated TLDH, lumbar spondylolithesis, previous spinal surgery and lack of radiographic materials. Ultimately, 57 cases were enrolled as the LDH group, which was composed of 28 males and 29 females, with an average age of 42.1 (18-66) years. Surgical indications were refractory sciatica pain, muscle weakness or bladder dysfunction. Forty-six patients had single-level herniation, 9 had twolevel herniation, and the other 2 patients had three-level of herniation. A total of 70 herniated discs were found between L3/4 and L5/S1, with 4 discs at L3/4, 44 discs at L4/5 and 22 discs at L5/S1. All LDH patients had complete radiographic materials similar to the TLDH group. More males were included in the TLDH group $\left(\chi^{2}=12.030\right.$, $P=0.001)$, and patients in these two groups had nearly equal ages $(t=0.844, P=0.400)$. Their medical records indicated that 52 patients in the TLDH group were or had ever been employed and $28.8 \%$ (15 patients) of them were manual workers, while 45 patients in the LDH group were or had ever been employed and $33.3 \%$ (15 patients) of them were manual workers. The average heights of male and female TLDH patients were $172.5 \pm 5.6 \mathrm{~cm}$ and $160.1 \pm 5.1 \mathrm{~cm}$ (Data on height were missing for $5 \mathrm{TLDH}$ patients and $2 \mathrm{LDH}$ patients). They were not significantly different from those of the LDH patients $[172.0 \pm 4.3 \mathrm{~cm}$ $(t=0.417, \quad P=0.678), \quad 159.5 \pm 4.2 \mathrm{~cm} \quad(t=0.399$, $P=0.692)]$. The average weight and body mass index (BMI) of the male TLDH patients were $80.4 \pm 14.1 \mathrm{~kg}$ and $26.6 \pm 3.8 \mathrm{~kg} / \mathrm{m}^{2}$. They were not significantly different from those of the male LDH patients $[75.1 \pm 11.2 \mathrm{~kg}$ $(t=1.709, \quad P=0.091), \quad 25.6 \pm 3.5 \mathrm{~kg} / \mathrm{m}^{2} \quad(t=1.114$, $P=0.269)$ ]. However, the female TLDH patients were in 
general heavier and plumper than the female LDH patients $[69.2 \pm 11.7$ vs. $61.1 \pm 8.8 \mathrm{~kg}(t=2.442, P=0.019)$; $26.7 \pm 3.8$ vs. $\left.24.0 \pm 3.1 \mathrm{~kg} / \mathrm{m}^{2}(t=2.313, P=0.026)\right]$.
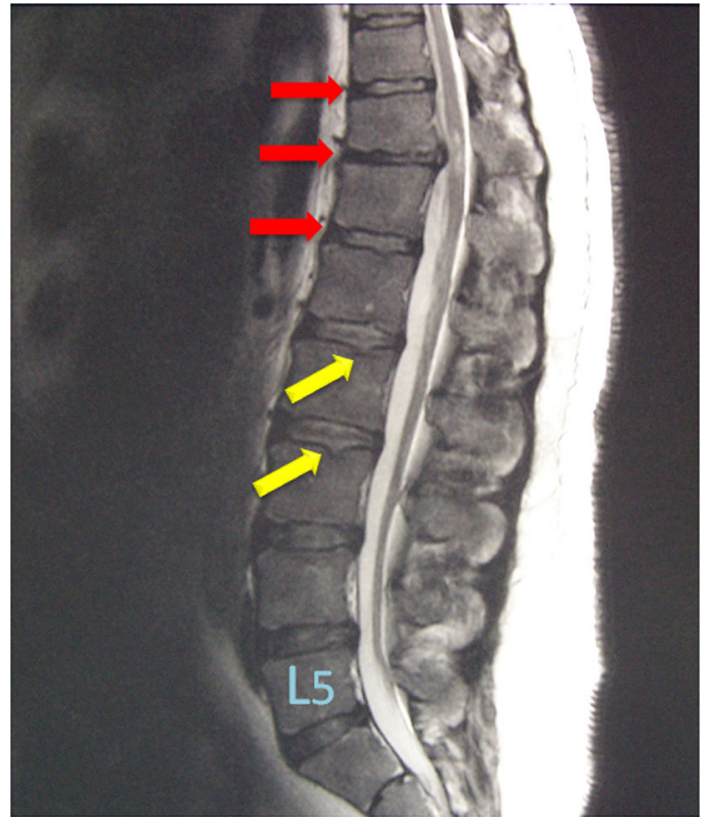

Fig. 1 This patient with T11/12 disc herniation has multiple Schmorl's nodes (yellow arrows) and irregular end plates (red arrows). Although only two $>5^{\circ}$ wedged vertebrae (T11 and T12) are observed, Schmorl's nodes (SN), irregular end plates (IE), wedgeshaped vertebrae (WV) and disc-space narrowing coexist. Thus, he was diagnosed with SD by the modified Heithoff's criterion
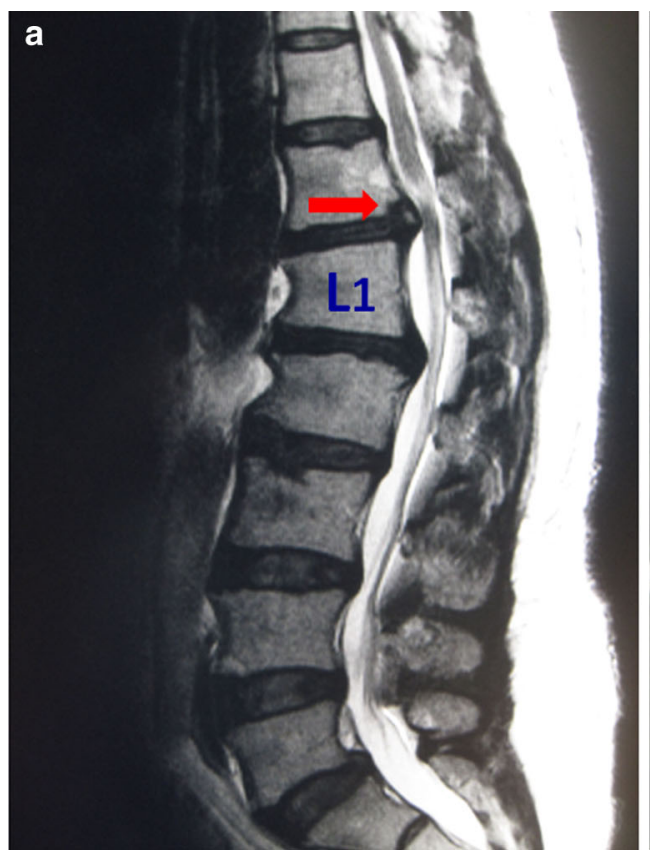

Fig. 2 Posterior bony avulsion (PBA) in a 35-year-old man. MR shows a defect at the posterior-inferior edge of the T12 vertebra, and the defect is filled with disc material (a). Axial CT at the same level
Radiographic review

Presence of radiographic signs of $S D$ in the TLDH and LDH groups

Radiographic signs of SD include SN, IE, PBA and WV. Their radiographic features are listed below. The incidences of patients having these signs and the average number of segments with these signs between T10/11 and L5/S1 in the TLDH group and the LDH group were compared. In addition, frequencies of these signs across all levels between T10/11 and L5/S1 were examined and compared level-by-level in the TLDH and LDH groups. The first author (a spine surgeon) reviewed the images independently.

1. SN: MR shows a defect in a vertebral end plate with a well-defined herniation pit in the vertebral body (Fig. 1).

2. IE: Vertebral end plate is irregular and sawtooth-like or wave-like on MR (Fig. 1).

3. PBA: Irregular bony defect in the posterior margin of the vertebral body with an avulsed bony edge that can be partially continuous with the vertebral body or clearly separated. MR reveals that the defect in the vertebral body is filled with disc material (Fig. 2).

4. WV: The vertebrae shows at least $5^{\circ}$ of anterior wedging on the scout image of the reconstructive CT (Fig. 3). A segment was recorded as positive if its

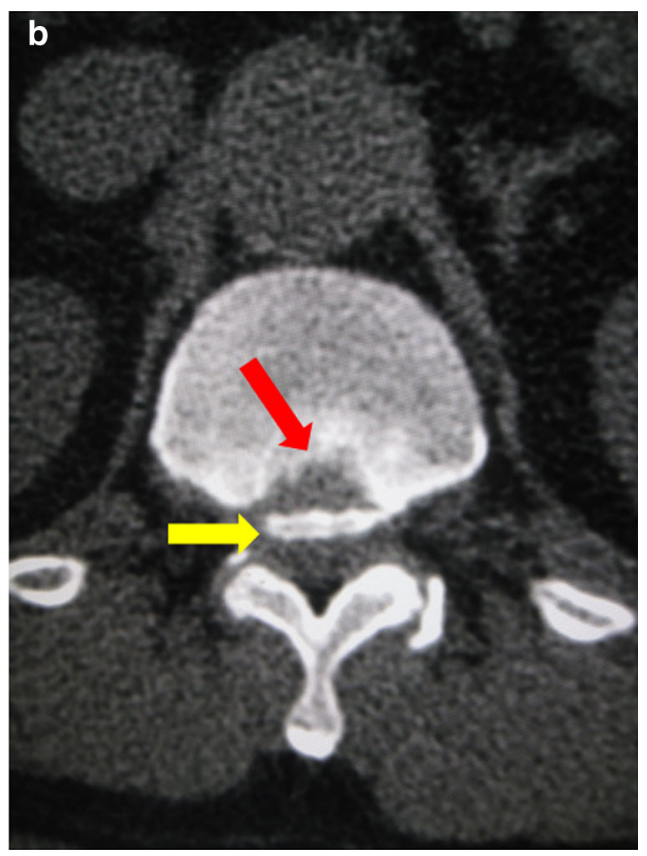

b demonstrates the irregular defect (red arrow) and the avulsed bony mass (yellow arrow) 


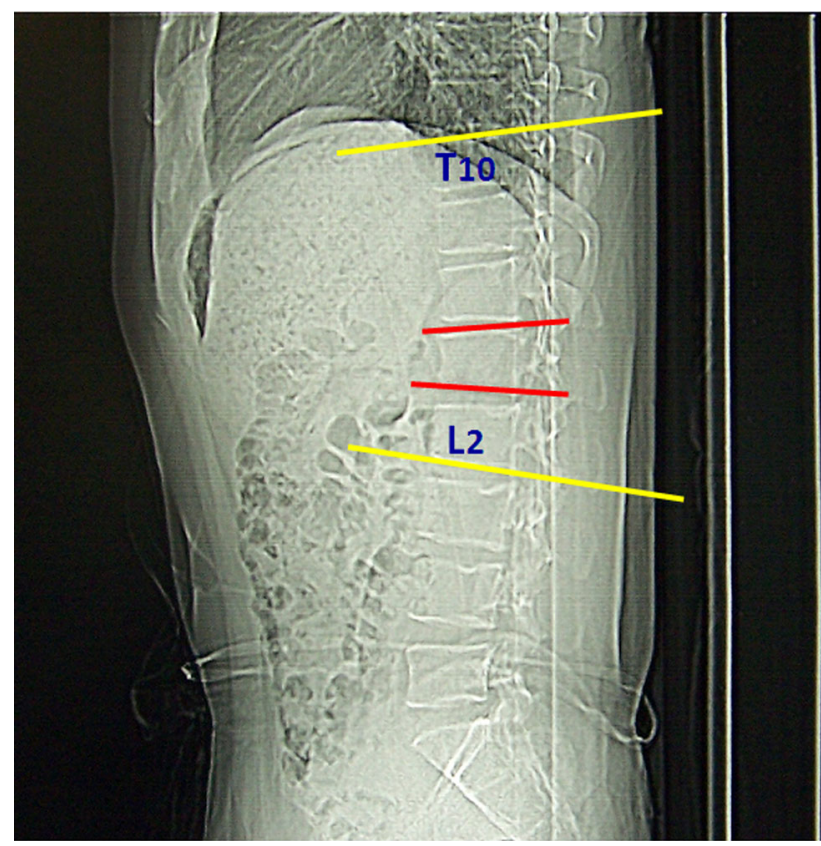

Fig. 3 CT scout image has the advantage of covering more vertebrae than the lateral lumbar roentgenogram. The wedging angle of the vertebra is measured as the included angle between the extension lines (red lines) of end plates of the same vertebra. The thoracolumbar kyphotic angle was measured as the included angle between the extension lines of the superior end plate of the T10 vertebra and the inferior end plate of the L2 vertebra (yellow lines)

adjacent superior or inferior vertebra was wedgeshaped.

\section{Comparison of the thoracolumbar kyphotic angle between the TLDH and LDH groups}

The thoracolumbar kyphotic angle referred to the included angle between the extension lines of the superior end plate of the T10 vertebrae and the inferior end plate of the L2 vertebrae. Because the superior end plate of T10 was not always covered by a single plain radiograph, the thoracolumbar kyphotic angle was measured from the preoperative scout image of the CT scan (Fig. 3). The mean kyphotic angles of the TLDH group and the LDH group were compared.

\section{Incidence of associated SD in the TLDH and LDH groups}

The incidences of associated SD in the TLDH and LDH groups were examined and compared. Scheuermann's disease was diagnosed either by the classical Sorenson's criterion of having at least three consecutive wedge-shaped vertebrae showing more than $5^{\circ}$ of anterior wedging or [5], by a modified Heithoff's criterion for SD [6]. In Heithoff's original study, 3 of the 5 signs on MR, including SN, IE,
Table 1 Comparison of incidences of patients with radiographic signs of SD in the TLDH group and the LDH group (Chi-square test)

\begin{tabular}{|c|c|c|c|c|}
\hline & $\begin{array}{l}\text { TLDH } \\
\text { group }\end{array}$ & $\begin{array}{l}\text { LDH } \\
\text { group }\end{array}$ & $\begin{array}{l}\chi^{2} \\
\text { value }\end{array}$ & $P$ value \\
\hline $\begin{array}{l}\text { Incidence of patients with } \\
\text { at least one SN }\end{array}$ & $\begin{array}{l}93.7 \% \\
(59 / 63)\end{array}$ & $\begin{array}{l}26.3(15 / \\
57)\end{array}$ & 57.397 & $<0.001$ \\
\hline $\begin{array}{l}\text { Incidence of patients with } \\
\text { at least one IE }\end{array}$ & $\begin{array}{l}95.2 \% \\
\quad(60 / 63)\end{array}$ & $\begin{array}{l}54.4 \% \\
(31 / 57)\end{array}$ & 27.251 & $<0.001$ \\
\hline $\begin{array}{l}\text { Incidence of patients with } \\
\text { at least one PBA }\end{array}$ & $\begin{array}{l}85.7 \% \\
(54 / 63)\end{array}$ & $\begin{array}{l}8.8 \% \\
(5 / 57)\end{array}$ & 43.371 & $<0.001$ \\
\hline $\begin{array}{l}\text { Incidence of patients with } \\
\text { at least one WV }\end{array}$ & $\begin{array}{l}96.8 \% \\
(61 / 63)\end{array}$ & $\begin{array}{l}42.1 \% \\
(24 / 57)\end{array}$ & 70.884 & $<0.001$ \\
\hline
\end{tabular}

$S N$ Schmorl's node, $I E$ irregular end plate, $P B A$ posterior bony avulsion of the vertebra, $W V$ wedge-shaped vertebra

WV, disc-space narrowing and disc dehydration, were necessary for the diagnosis of SD [6]. However, because disc-space narrowing and disc dehydration are highly nonspecific, we modified Heithoff's criterion to "The fulfillment of 4 signs that must include SN, IE and WV of the aforementioned 5 signs is necessary to diagnose SD" (Fig. 1). In this part of the study, two spine surgeons (the first author and the fourth author) reviewed the images independently. The inter-rater judgment consistency between these observers was examined using Kappa analysis.

The relationship between radiographic signs of SD and disc herniation

In the TLDH group, from T10/11 to L1/2 (63 patients, 252 segments), the incidences of disc herniation at the segments with SN, IE, PBA and WV were compared to the incidence of disc herniation at the segments without any Scheuermann's sign.

Statistical analysis

Chi-square tests, rank-sum test and $t$ test were used in the above-mentioned comparisons, and the $\alpha$ value was set at 0.05. SPSS 13.0 (SPSS, U.S.A) was used for data analysis.

\section{Results}

Frequencies of radiographic signs of SD in TLDH and LDH patients

SN, IE, PBA and WV were all more frequently observed in TLDH patients than in LDH patients (Tables 1, 2; Fig. 4). Comparison across all levels between T10/11 and L5/S1 showed similar results except for at $\mathrm{L} 4 / 5$ and $\mathrm{L} 5 / \mathrm{S} 1$. There 
Table 2 Comparison of the average number of segments with radiographic signs of SD between T10/11 and L5/S1 in the TLDH group and the LDH group (Rank sum test)

\begin{tabular}{|c|c|c|c|c|}
\hline & TLDH group & LDH group & $Z$ value & $P$ value \\
\hline $\begin{array}{l}\text { Average number of segments } \\
\text { with SN }\end{array}$ & $\begin{array}{l}\text { Median } 3 \text { (range } 0-8 \text {, lower quartile } 2 \text {, } \\
\text { upper quartile 5) }\end{array}$ & $\begin{array}{l}\text { Median } 0 \text { (range } 0-5 \text {, lower quartile } 0 \text {, } \\
\text { upper quartile } 1)\end{array}$ & -8.140 & $<0.001$ \\
\hline $\begin{array}{l}\text { Average number of segments } \\
\text { with IE }\end{array}$ & $\begin{array}{l}\text { Median } 4 \text { (range } 0-8, \text { lower quartile } 2 \text {, } \\
\text { upper quartile } 6 \text { ) }\end{array}$ & $\begin{array}{l}\text { Median } 1 \text { (range } 0-6 \text {, lower quartile } 0 \text {, } \\
\text { upper quartile } 1 \text { ) }\end{array}$ & -7.510 & $<0.001$ \\
\hline $\begin{array}{l}\text { Average number of segments } \\
\text { with PBA }\end{array}$ & $\begin{array}{l}\text { Median } 1 \text { (range } 0-3 \text {, lower quartile } 1 \text {, } \\
\text { upper quartile } 1 \text { ) }\end{array}$ & $\begin{array}{l}\text { Median } 0 \text { (range } 0-1 \text {, lower quartile } 0 \text {, } \\
\text { upper quartile } 0 \text { ) }\end{array}$ & -6.344 & $<0.001$ \\
\hline $\begin{array}{l}\text { Average number of segments } \\
\text { with WV }\end{array}$ & $\begin{array}{l}\text { Median } 3 \text { (range } 0-7 \text {, lower quartile } 3 \text {, } \\
\text { upper quartile } 4 \text { ) }\end{array}$ & $\begin{array}{l}\text { Median } 0 \text { (range } 0-5 \text {, lower quartile } 0 \text {, } \\
\text { upper quartile } 3 \text { ) }\end{array}$ & -8.270 & $<0.001$ \\
\hline
\end{tabular}

Data are not normally distributed, median and the rank sum test were used here

$S N$ Schmorl's node, $I E$ irregular end plate, $P B A$ posterior bony avulsion of the vertebra, $W V$ wedge-shaped vertebra

Table 3 Comparison of the incidence of $\mathrm{SN}$ across all levels (Chi-square test)

$S N$ Schmorl's node, $I E$ irregular end plate, $P B A$ posterior bony avulsion of the vertebra, $W V$ wedge-shaped vertebra

\begin{tabular}{|c|c|c|c|c|}
\hline Level and defect & TLDH group $(n=63)$ & LDH group $(n=57)$ & $\chi^{2}$ value & $P$ value \\
\hline T10/11 (SN) & $29(46.0 \%)$ & $1(1.8 \%)$ & 31.289 & $<0.001$ \\
\hline $\mathrm{T} 11 / 12$ (SN) & $29(46.0 \%)$ & $4(7.0 \%)$ & 22.846 & $<0.001$ \\
\hline T12/L1 (SN) & $32(50.8 \%)$ & $1(1.8 \%)$ & 36.095 & $<0.001$ \\
\hline $\mathrm{L} 1 / 2(\mathrm{SN})$ & $39(61.9 \%)$ & $4(7.0 \%)$ & 39.208 & $<0.001$ \\
\hline $\mathrm{L} 2 / 3(\mathrm{SN})$ & $34(54.0 \%)$ & $3(5.3 \%)$ & 33.286 & $<0.001$ \\
\hline L3/4 (SN) & $23(36.5 \%)$ & $2(3.5 \%)$ & 19.758 & $<0.001$ \\
\hline L4/5 (SN) & $13(20.6 \%)$ & $6(10.5 \%)$ & 2.295 & $<0.001$ \\
\hline L5/S1 (SN) & $3(4.8 \%)$ & $2(3.5 \%)$ & 0.000 & 1.000 \\
\hline T10/11 (IE) & $28(44.4 \%)$ & $1(1.8 \%)$ & 29.758 & $<0.001$ \\
\hline T11/12 (IE) & $41(65.1 \%)$ & $4(7.0 \%)$ & 43.043 & $<0.001$ \\
\hline T12/L1 (IE) & $44(69.8 \%)$ & $3(5.3 \%)$ & 52.378 & $<0.001$ \\
\hline $\mathrm{L} 1 / 2$ (IE) & $40(63.5 \%)$ & $0(0.0 \%)$ & 54.286 & $<0.001$ \\
\hline L2/3 (IE) & $32(50.8 \%)$ & $4(7.0 \%)$ & 27.308 & $<0.001$ \\
\hline L3/4 (IE) & $26(41.3 \%)$ & $6(10.5 \%)$ & 14.463 & $<0.001$ \\
\hline L4/5 (IE) & $16(25.4 \%)$ & $19(33.3 \%)$ & 0.912 & 0.339 \\
\hline L5/S1 (IE) & $6(9.5 \%)$ & $12(21.1 \%)$ & 3.120 & 0.077 \\
\hline T10/11 (PBA) & $0(0.0 \%)$ & $0(0.0 \%)$ & Fisher exact test & 1.000 \\
\hline T11/12 (PBA) & $24(38.1 \%)$ & $0(0.0 \%)$ & 27.143 & $<0.001$ \\
\hline T12/L1 (PBA) & $25(39.7 \%)$ & $0(0.0 \%)$ & 28.571 & $<0.001$ \\
\hline L1/2 (PBA) & $14(22.2 \%)$ & $0(0.0 \%)$ & 14.340 & $<0.001$ \\
\hline L2/3 (PBA) & $0(0.0 \%)$ & $0(0.0 \%)$ & Fisher exact test & 1.000 \\
\hline L3/4 (PBA) & $1(1.6 \%)$ & $0(0.0 \%)$ & Fisher exact test & 1.000 \\
\hline L4/5 (PBA) & $0(0.0 \%)$ & $3(5.3 \%)$ & 1.584 & 0.208 \\
\hline L5/S1 (PBA) & $0(0.0 \%)$ & $2(3.5 \%)$ & Fisher exact test & 0.224 \\
\hline T10/11 (WV) & $27(42.9 \%)$ & $9(15.8 \%)$ & 10.440 & 0.001 \\
\hline T11/12 (WV) & $52(82.5 \%)$ & $18(31.6 \%)$ & 31.974 & $<0.001$ \\
\hline T12/L1 (WV) & $57(90.5 \%)$ & $23(40.4 \%)$ & 33.835 & $<0.001$ \\
\hline L1/2 (WV) & $51(81.0 \%)$ & $20(35.1 \%)$ & 26.055 & $<0.001$ \\
\hline L2/3 (WV) & $24(38.1 \%)$ & $4(7.0 \%)$ & 16.157 & $<0.001$ \\
\hline L3/4 (WV) & $8(12.7 \%)$ & $0(0.0 \%)$ & 5.849 & 0.016 \\
\hline L4/5 (WV) & $1(1.6 \%)$ & $0(0.0 \%)$ & Fisher exact test & 1.000 \\
\hline L5/S1 (WV) & $1(1.6 \%)$ & $0(0.0 \%)$ & Fisher exact test & 1.000 \\
\hline
\end{tabular}


Table 4 Incidences of associated SD in the TLDH group and the LDH group (Chi-square test)

\begin{tabular}{|c|c|c|c|c|}
\hline & $\begin{array}{l}\text { TLDH } \\
\text { group }\end{array}$ & $\begin{array}{l}\text { LDH } \\
\text { group }\end{array}$ & $\begin{array}{l}\chi^{2} \\
\text { value }\end{array}$ & $P$ value \\
\hline $\begin{array}{l}\text { Incidence of associated } \\
\text { SD }\end{array}$ & $\begin{array}{l}95.2 \% \\
\quad(60 / 63)\end{array}$ & $\begin{array}{l}17.5 \% \\
(10 / 57)\end{array}$ & 74.320 & $<0.001$ \\
\hline $\begin{array}{l}\text { Number of patients } \\
\text { diagnosed with SD by } \\
\text { Sorensen's criterion }\end{array}$ & $\begin{array}{l}35 \\
\quad(55.6 \%)\end{array}$ & 8 & 22.437 & $<0.001$ \\
\hline $\begin{array}{l}\text { Number of patients } \\
\text { diagnosed with SD by } \\
\text { the modified } \\
\text { Heithoff's criterion }\end{array}$ & $\begin{array}{l}58 \\
\quad(92.1 \%)\end{array}$ & 6 & 79.936 & $<0.001$ \\
\hline $\begin{array}{l}\text { Number of patients that } \\
\text { fulfilled both criteria }\end{array}$ & $\begin{array}{l}33 \\
\quad(52.4 \%)\end{array}$ & $3(5.3 \%)$ & 31.636 & $<0.001$ \\
\hline
\end{tabular}

were no significant differences on the incidences of IE, PBA and WV at L4/5 and L5/S1. In addition, no significant difference on the incidence of SN was observed at L5/S1 (Table 3; Fig. 4).

Comparison of thoracolumbar kyphotic angles between the TLDH group and LDH group

The mean kyphotic angle was $16.9^{\circ} \pm 6.4^{\circ}\left(5.4^{\circ}-35.8^{\circ}\right)$ in the TLDH patients and $7.6^{\circ} \pm 5.2^{\circ}\left(0.8^{\circ}-26.6^{\circ}\right)$ in the $\mathrm{LDH}$ patients. The difference was statistically significant $(t=8.683, P=0.000)$.

Incidence of associated SD in the TLDH and LDH groups

The incidence of associated SD in the TLDH group was higher than that in the LDH group, no matter whether evaluation relied on Sorensen's criterion or the modified Heithoff's criterion (Table 4).

The data presented here (Table 4) were from the first author. The inter-rater consistency between the first author and the fourth author was evaluated using Kappa analysis. The Kappa values for the diagnosis of SD in the TLDH group by Sorenson' criteria, SD in the TLDH group by modified Heithoff's criteria, SD in the LDH group by
Sorenson's criteria and SD in the LDH group by modified Heithoff's criteria were $0.737,0.816,0.793$ and 0.782 , respectively $(P=0.000)$, showing good consistency in all items.

The relationship between radiographic signs of SD and disc herniation

Disc herniation occurred more frequently at segments with SN, IE, PBA or WV than at segments where no Scheuermann's sign was found (Table 5).

\section{Discussion}

Our study suggested that symptomatic TLDH is a special form of SD. As illustrated by the results, patients in the TLDH group frequently had morphological defects at the end plates and vertebrae characteristic of SD, and most patients met the diagnostic criterion for SD. Gille et al. reported 18 cases with hard thoracic herniated discs, $72 \%$ of which were situated between $\mathrm{T} 8$ and $\mathrm{T} 12$, a region that overlaps with the thoracolumbar spine. They found that $56 \%$ of these patients had sequelae of SD [13]. This was, to some extent, in accordance with our finding that $55.6 \%$ of TLDH patients could be diagnosed with SD (Table 4), according to Sorensen's criteria, which Gille et al. [13] also used. The reason, we included a control group of LDH patients is to prevent excessive sensitivity to the identification of SD. The level-by-level comparison between the two groups showed that radiographic signs of SD in the TLDH group dominate in every level from T10/11 to L3/4, (Fig. 4) a range that exceeds the thoracolumbar junction area, suggesting primary SD rather than primary disc degeneration. In addition, the skewed sex ratio (more males) in the TLDH group corresponds well to the literature's description of "thoracolumbar SD" [6, 7, 9] or "atypical lumbar SD" [18], and the increased thoracolumbar kyphotic angle (averaging $16.9^{\circ}$ ) in the TLDH group is suggestive of a mild version of Scheuermann's kyphosis. However, when compared with conventional concepts in SD, two unique characteristics were found in

Table 5 Association between radiographic signs of SD and disc herniation (Chi-square test)

\begin{tabular}{|c|c|c|c|c|c|}
\hline & Number of segments & Disc herniation (\%) & No disc herniation (\%) & $\chi^{2}$ value & $P$ value \\
\hline $\mathrm{SN}$ & 129 & $41(31.8 \%)$ & $88(68.2 \%)$ & 10.921 & 0.001 \\
\hline IE & 153 & $70(45.8 \%)$ & $83(54.2 \%)$ & 20.333 & $<0.001$ \\
\hline PBA & 63 & $61(96.8 \%)$ & $2(3.2 \%)$ & 82.185 & $<0.001$ \\
\hline WV & 187 & $71(38.0 \%)$ & $116(62.0 \%)$ & 15.032 & $<0.001$ \\
\hline No Scheuermann's sign & 32 & $1(3.1)$ & $31(96.9 \%)$ & - & - \\
\hline
\end{tabular}

$S N$ Schmorl's node, $I E$ irregular end plate, $P B A$ posterior bony avulsion of the vertebra, $W V$ wedge-shaped vertebra 


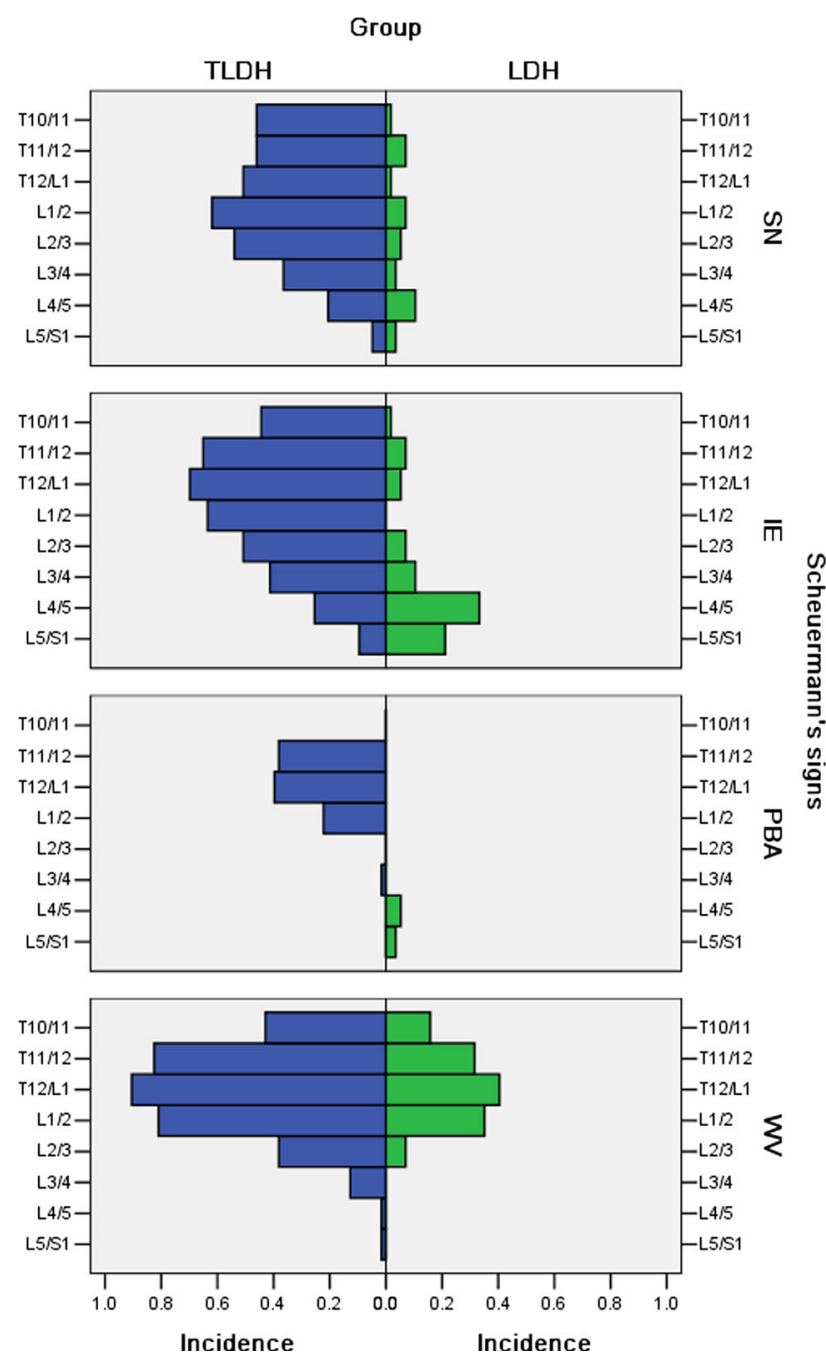

Fig. 4 Schmorl's node (SN), irregular end plate (IE), posterior bony avulsion of the vertebra (PBA) and wedge-shaped vertebra (WV) are more frequently observed in TLDH patients than in LDH patients across almost all levels between T10/11 and L5/S1

this series of TLDH patients with a high ratio of associated SD. First, the age range tended toward middle-aged adults rather than adolescents. Second, all patients suffered myelopathy or radiculopathy that warranted surgery, whereas neurological complications of SD; especially, in adults with mild kyphosis, were considered rare in the past $[5,19]$.

Adequate evidence has shown that SD and its radiographic changes promote disc degeneration [6-9, 20]. This was also demonstrated in our study in which SN, IE, PBA and WV were all found to enhance disc herniation in the TLDH group (Table 5). Histological studies have revealed abnormal cartilage matrix of the vertebral end plate in SD patients, suggesting a developmental structural weakness $[21,22]$. Genetic bases for the pathogenesis of SD or the associated disc lesion were also identified [23-25]. The intrinsic weakness of discs due to SD was considered to be one major contributing factor for premature lumbar disc degeneration found in some young patients $[6,9,10]$. From our study, it can be assumed that the synergism of the innate biomechanical weakness of the discs due to SD and daily stress over time leads to disc protrusion at the relatively immobilized thoracolumbar spine in this TLDH series. Seven patients in the TLDH group developed symptoms after traumatic incidents. However, there was evidence that a vulnerable disc may already exist before external forces occur [16].

In the TLDH group, the high incidence of PBA $(85.7 \%)$ and the high incidence $(96.8 \%)$ of disc herniation at segments with PBA suggested an active pathologic role for PBA in symptomatic TLDH. PBA was considered an avulsion of the posterior ring apophysis due to the lack of fusion between the separated bony mass and the vertebral body [8]. It was frequently found to appear together with other signs of SD [8]. Previous studies reported PBA would occur at the lower lumbar spine at a low incidence and tend to promote symptomatic disc herniation $[8,26,27]$. The high incidence of PBA in symptomatic TLDH patients may be partly attributed to increased thoracolumbar kyphosis, as observed in this series, which could produce increased stretching stress on the posterior annulus of the discs. Morphologically, PBA corresponds to the "anterior Schmorl's node" [6], which itself may be anterior bony avulsion, found in "lumbar SD" because of the lordosis of the lumbar spine. It is possible that increased thoracolumbar kyphosis in symptomatic TLDH patients accelerates posterior disc herniation by means of PBA, whereas the lordosis of the lumbar spine, in contrast, slows disc herniation by an opposing mechanism. This finding may explain why numerous symptomatic TLDH patients do not have disc herniation in the lower lumbar spine which is naturally more mobile than the thoracolumbar spine.

The results of this study showed marked radiographic similarities between symptomatic TLDH and SD, and a strong tendency of SD's signs to promote disc herniation in TLDH patients. These findings suggest that symptomatic TLDH should be seen as a truly different surgical entity, that is, a special form of SD, rather than just an indicator of a failing back. Viewing this entity in this way can help in explaining the etiology of TLDH. As for its clinical significance, currently, we should pay attention to the thoracolumbar discs in patients where radiological signs of SD are present on their spine images. In the future, if a definite association between symptomatic TLDH and SD is established, it will be possible to offer prevention and treatment strategies against SD during the course of caring for TLDH patients. Future studies on the natural history of thoracolumbar disc degeneration in Scheuermann individuals, as well as a comparison of the disc histology and genetics 
between TLDH and SD, would lend additional credence to their relationship.

\section{Conclusion}

The high proportion of associated SD and the tendency of SD's signs to promote disc herniation in symptomatic TLDH patients suggest a close relationship between these two disorders. Symptomatic TLDH should be seen as a truly different surgical entity, that is, a special form of SD rather than just an indicator of a failing back.

\section{Conflict of interest None.}

Open Access This article is distributed under the terms of the Creative Commons Attribution License which permits any use, distribution, and reproduction in any medium, provided the original author(s) and the source are credited.

\section{References}

1. Tokuhashi Y, Matsuzaki H, Uematsu Y et al (2001) Symptoms of thoracolumbar junction disc herniation. Spine 26:E512-E518

2. Otani K, Yoshida M, Fujii E et al (1988) Thoracic disc herniation. Surgical treatment in 23 patients. Spine 13:1262-1267

3. Kim JS, Lee SH, Moon KH et al (2009) Surgical results of the oblique paraspinal approach in upper lumbar disc herniation and thoracolumbar junction. Neurosurg 65:95-99

4. Sanderson SP, Houten J, Errico T et al (2004) The unique characteristics of "upper" lumbar disc herniations. Neurosurg 55:385-389

5. Lowe TG (1990) Current concepts review. Scheuermann disease. J Bone Joint Surg Am 72:940-945

6. Heithoff KB, Gundry CR, Burton CV et al (1994) Juvenile discogenic disease. Spine 19(3):335-340

7. Paajanen H, Alanen A, Erkintalo M et al (1989) Disc degeneration in Scheuermann disease. Skeletal Radiol 18:523-526

8. Laredo JD, Bard M, Chretien J et al (1986) Lumbar posterior marginal intra-osseous cartilaginous node. Skeletal Radiol 15:201-208

9. Blumenthal SL, Roach J, Herring JA (1987) Lumbar Scheuermann's. A clinical series and classification. Spine 12:929-932

10. Clevand RH, Delong GR (1981) The relationship of juvenile lumbar disc disease and Scheuermann's disease. Pediatr Radiol 10:161-164
11. Lesoin F, Leys D, Rousseaux M et al (1987) Thoracic disk herniation and Scheuermann's disease. Eur Neurol 26:145-152

12. Hafner RHV, Surrey C (1952) Localised osteochondritis (Scheuermann's disease). J Bone Joint Surg 34B:38-40

13. Gille O, Soderlund C, Razafimahandri HJC et al (2006) Analysis of hard thoracic herniated discs: review of 18 cases operated by thoracoscopy. Eur Spine J 15:537-542

14. Hsu K, Zucherman J, Shea W et al (1990) High lumbar disc degeneration. Incidence and etiology. Spine 15:679-682

15. Kapetanos GA, Hantzidis PT, Anagnostidis KS et al (2006) Thoracic cord compression caused by disk herniation in Scheuermann's disease. Eur Spine J 15(5):553-558

16. Song KS, Yang JJ (2011) Acutely progressing paraplegia caused by traumatic disc herniation through posterior Schmorl's node opening into the spinal canal in lumbar Scheuermann's disease. Spine 36:E1588-E1591

17. Bhojraj SY, Dandawate AV (1994) Progressive cord compression secondary to thoracic disc lesions in Scheuermann's kyphosis managed by posterolateral decompression, interbody fusion and pedicular fixation. A new approach to management of a rare clinical entity. Eur Spine J 3:66-69

18. Mandell GA, Morales RW, Harcke HT et al (1993) Bone scintigraphy in patients with atypical lumbar Scheuermann disease. J Pediatr Ortho 13:622-627

19. Arlet V, Schlenzka D (2005) Scheuermann's kyphosis: surgical management. Eur Spine J 14:817-827

20. Stoddard A, Osborn JF (1979) Scheuermann's disease or spinal osteochondrosis. J Bone Joint Surg Br 61:56-58

21. Ippolito E, Ponseti I (1981) Juvenile kyphosis: histological and histochemical studies. J Bone Joint Surg Am 63:175-182

22. Aufdermaur M (1981) Juvenile kyphosis (Scheuermann's disease): radiography, histology and pathogenesis. Clin Orthop 154:166-174

23. Karppinen J, Pääkköö E, Paassilta $P$ et al (2003) Radiologic phenotypes in lumbar MR imaging for a gene defect in the COL9A3 gene of type IX collagen. Radiology 227:143-148

24. Williams FMK, Manek NJ, Sambrook PN et al (2007) Schmorl's nodes: common, highly heritable, and related to lumbar disc disease. Arth Rheum 57(5):855-860

25. Gustavel M, Beals RK (2002) Scheuermann's disease of the lumbar spine in identical twins. Am J Roentgenol 179:1078-1079

26. Dietemann JL, Runge M, Badoz A et al (1988) Radiology of posterior lumbar apophyseal ring fractures: report of 13 cases. Neuroradiology 30:337-344

27. Asazuma T, Nobuta M, Sato M et al (2003) Lumbar disc herniation associated with separation of the posterior ring of apophysis: analysis of five surgical cases and review of the literature. Acta Neurochir 145:461-466 